\title{
Engenheiros consultores: profissionais do desenvolvimento territorial e urbano - 1960-1970
}

PULHEZ, Magaly Marques

Resumo

O trabalho propõe introduzir uma reflexão sobre a historicidade de um personagem usualmente pouco tratado na galeria de estudos sobre os temas do desenvolvimento territorial e urbano: o engenheiro consultor. As origens da Engenharia Consultiva na verdade confundem-se com o próprio desenvolvimento econômico do país nas primeiras décadas do século XX, quando identificamos os momentos primordiais de arranque rumo à industrialização e à urbanização. Além disso, trata-se também de um processo evidentemente ligado à própria afirmação de um campo profissional, quando os engenheiros gradualmente passam a se deslocar das atividades manufatureiras dos canteiros de obra para os escritórios de projeto e consultoria, reivindicando seu conhecimento técnico e científico sobre o processo de produção do espaço, seu posto propriamente gerencial na tarefa de contribuir ao desenvolvimento nacional. No campo de especialidades em que transitam, estes profissionais alcançarão o comando de grandes empresas de engenharia do setor consultivo que, por sua vez, irão se espraiar, sobretudo entre os anos 1960 e 1970, por áreas de atuação as mais diversas - desde o projeto de hidrelétricas, estradas e portos ao desenvolvimento de planos diretores locais, numa movimentação alavancada pelos altos investimentos estatais direcionados à construção da infraestrutura de um país em franco processo de expansão urbana.

Palavras-chave: Engenheiros Consultores. Empresas de Engenharia Consultiva. Campo Profissional. Desenvolvimento Urbano. Expansão Territorial.

\begin{abstract}
:
This paper reflects upon the historicity of a character often overlooked in the gallery of studies pertaining to topics of territorial and urban development: the consulting engineer. The origins of consulting engineering in fact merge with Brazil's economic boom during the first decades of the twentieth century, a period which marked the early stages of industrialization and urbanization in this country. Moreover, this period is linked to the very assertion of engineering as a professional field, when engineers gradually moved from manufacturing activities at construction sites to design and consulting offices, claiming their technical and scientific knowledge of the space production process, as well as their managerial capacity in the task of contributing to national development. Within the field of specialities they acted in, these professionals acquired control of large engineering companies in the consulting sector which, in turn, began to operate in various areas of expertise, especially between 1960 and 1970 - from designing hydroelectric plants, roads, and ports to developing local master plans, stimulated by high government investments set on constructing the infrastructure of a country then undergoing a major urban expansion process.
\end{abstract}

Keywords: Consulting Engineers. Consulting Engineering Firms. Professional Field. Urban Development. Territorial Expansion 


\section{Introdução}

A reconstituição, em pequena escala, das particularidades de um campo profissional específico é parte fundamental do processo de construção da historiografia do urbano tanto quanto a aposta em grandes narrativas de abordagem transdisciplinar. É a partir desta premissa que o presente trabalho propõe introduzir uma reflexão sobre a historicidade de um personagem usualmente pouco tratado na galeria de estudos sobre os temas do desenvolvimento territorial e urbano: o engenheiro consultor.

As origens da Engenharia Consultiva na verdade confundem-se com o próprio desenvolvimento econômico do país nas primeiras décadas do século $X X$, quando identificamos os momentos primordiais de arranque rumo à industrialização e à urbanização. Mas, além disso, trata-se, aqui, de um processo evidentemente ligado à própria afirmação de um campo profissional, quando os engenheiros gradualmente passam a se deslocar das atividades manufatureiras dos canteiros de obra para os escritórios de projeto e consultoria, reivindicando seu conhecimento técnico e científico sobre o processo de produção do espaço, seu posto propriamente gerencial na tarefa de contribuir ao desenvolvimento nacional.

No campo de especialidades em que transitam, estes profissionais, como se verá, alcançarão o comando de grandes empresas de engenharia do setor consultivo que, por sua vez, irão se espraiar, sobretudo entre os anos 1960 e 1970, por áreas de atuação as mais diversas - desde o projeto de hidrelétricas, estradas e portos ao desenvolvimento de planos diretores locais, numa movimentação alavancada pelos altos investimentos estatais direcionados à construção da infraestrutura de um país em franco processo de expansão urbana.

\section{Engenharia Consultiva: a afirmação de um campo profissional}

\footnotetext{
Até meados da década de 1940, o negócio da construção em São Paulo envolvia, em geral, dois tipos de firmas particulares: aquelas que possuíam seus operários, equipamentos e maquinaria, e aquelas que trabalhavam por administração [...]. Ambos os tipos podiam se dedicar ou à tarefa unificada da construção ou a tarefas especializadas: estruturas de concreto armado, cantaria, carpintaria, detalhes de estuque, instalações elétricas e hidráulicas, serralheria, jardinagem e mesmo empreita de mão-de - obra [...]
}

\begin{abstract}
As firmas particulares - os escritórios técnicos, como às vezes eram chamadas - cuidavam de todas as etapas necessárias para a realização de uma obra (ou da tarefa em que se especializavam): o projeto, o orçamento e a execução.

[...] Não existiam firmas que se dedicavam apenas à feitura de projetos, já que seu custo estava incluído no preço total da obra. [...] o projeto não se caracterizava como mercadoria para o proprietário de um empreendimento imobiliário, para quem ficava, aparentemente, de graça. (FICHER, 2005, p. 240-241).
\end{abstract}

A anotação de Sylvia Ficher lhe serve de mote à reconstrução do contexto em que projeto e construção passam a ser disputados como serviços específicos, clivados. Nesse momento, ou seja, ainda em meados dos anos 1920, arquitetos passavam a defender o exercício projetual como exclusivo de seu métier (que, ademais, haveria de ser respeitado por seu estatuto artístico, acima dos "problemas da engenharia na construção"1), ainda que com pouca ressonância no campo profissional efetivo, que de fato reunia, no mesmo espaço dos negócios da construção, engenheiros, arquitetos e construtores (práticos não diplomados), confundindo-os numa prática de ofício comum, sem atribuições muito claras sobre o comando das atividades.

Ficher segue seu texto nos dando pistas a respeito dessa cisão que logo mais se efetivaria por completo, inevitavelmente, como de fato ocorreu: a adoção da atividade exclusiva de projetista seria "o itinerário seguido pela classe [dos arquitetos] para superar as falhas que via na regulamentação quanto à sua individualidade profissional e, de quebra, valorizar-se com a aura do trabalho artístico" (FICHER, 2005, p. 244). ${ }^{2}$

$\mathrm{Na}$ verdade, na rotina interna de diversas empresas construtoras, essa independência do trabaIho do arquiteto já acontecia na prática. Santos (2008) cita um depoimento de 1933, colhido do

\footnotetext{
1. Como afirmara Christiano Stockler das Neves, então diretor do curso de engenheiro-arquiteto da Escola de Engenharia Mackenzie (FICHER, 2005, p. 243).

2. O registro mais emblemático dessa trajetória seria o escritório de projetos de Rino Levi, arquiteto formado na Itália em 1926 e que, em meados de 1930, decide, já radicado em São Paulo, dedicar-se exclusivamente ao desenvolvimento projetual (FICHER, 2005, p. 244-245). Mas, há outros, inclusive anteriores a Levi, recuperados por Rabelo (2011) e Freitas (2011), no Rio de Janeiro, como é o caso do arquiteto peruano Robert Prentice, diplomado na Inglaterra, e do escritório Heitor de Melo, comandado pelos arquitetos Archimedes Memória e Francisque Cuchet, o mais importante da cidade na década de 1920.
} 
periódico $A$ Casa, em que o empreiteiro Eduardo Pederneiras, dos grandes de então, na cidade do Rio de Janeiro, declara objetivamente que "o arquiteto é aquele que projeta" e que "arquiteto e construtor são duas entidades completamente separadas". Sua firma, dizia ele, estava organizada em seções autônomas de projeto e construção, ainda que trabalhassem todos em regime de cooperação. Essa separação já era comum na França e nos Estados Unidos e certamente, segundo suas convicções, não tardaria a se oficializar no Brasil (SANTOS, 2008, p. 259). Sylvia Ficher (2005), por sua vez, lembra que nos órgãos de obras públicas e nas contratações de projeto pelo estado e pelo município de São Paulo também já era possível encontrar indícios dessa separação há alguns anos. ${ }^{3}$

Havia, no entanto, uma terceira figura contraposta entre arquitetos e engenheiros - a do já mencionado construtor não diplomado (o mestre de obra), o que complexificava ainda mais a condição da disputa em jogo, visto que tornava também o papel dos engenheiros pouco preciso: seriam eles, os engenheiros, detentores, afinal, de um conhecimento "técnico" relacionado à segurança, à economia, à eficiência das construções ainda não valorizado à altura de sua importância. Portanto, também aí foram necessárias verdadeiras campanhas de apelo e legitimação do ofício, ligadas à expansão dos cursos de engenharia, à regulamentação profissional e também à normalização técnica do emprego dos materiais.

Na larga história da engenharia brasileira recontada por Telles (1994), durante este processo de luta pela valorização profissional e de aumento do mercado de trabalho, a insistência nos processos de controle do canteiro, de administração geral e de controle técnico da obra contribuíram para a "transição gradual dos antigos 'engenheiros enciclopédicos' para os engenheiros especialistas nos diversos ramos da profissão" (TELLES, 1994, p. 705). A construção de ferrovias, portos, serviços de abastecimento d'água, minas e metalurgia já vinha fazendo

\footnotetext{
3. A autora cita um exemplo precoce de independência projetual: "a série de projetos de escolas e cadeias feita por Vitor Dubugras como funcionário da Secretaria da Agricultura, Comércio e Obras Públicas na década de 1890" (FICHER, 2005, p. 241).

4. Conforme observam Gitahy e Pereira (2002), é na década de 1930 que os conflitos presentes no cotidiano da organização do trabalho da construção vão encontrar suas "saídas": de um lado, qualificando a atuação técnica e gerencial dos engenheiros (e também arquitetos) e, de outro, desqualificando o trabalho direto no canteiro do mestre de obras, relegado à instransponível subordinação aos diplomados detentores de conhecimento técnico científico.
}

destacar engenheiros importantes, que iam aos poucos se distinguindo em cada uma dessas áreas, como é o caso de Saturnino de Brito e Alfredo Lisboa. ${ }^{4}$

Saturnino de Brito, inclusive, é considerado por Telles (1993) como um dos precursores da "engenharia consultiva no Brasil, com a fundação, em 1920, do escritório de engenharia que levava seu nome":

\author{
São interessantes os anúncios e impressos \\ desse escritório, onde está dito que "não se \\ encarrega de construções e empreitadas", \\ dedicando-se somente "a estudos, projetos e \\ pareceres, bem como administração e \\ fiscalização de obras, sob regime \\ exclusivamente técnico". (TELLES, 1993, p. 374).
}

No entanto, os domínios "técnicos" do engenheiro na atividade construtiva, o seu interesse em requisitar para si o comando e a direção das obras, acontecerão de forma mais incisiva justamente no contexto analisado por Roberto Estaáquio dos Santos e por Maria Luiza Freitas: ambos, corroborando argumentos também defendidos por Telles (1993), nos introduzem uma questão que parece fundamental para entender o modo como, em meio aos engenheiros civis, virá a suceder-se um desmembramento gradativo das funções do ofício - engenheiros construtores, projetistas, calculistas, gerenciadores -, sugerindo que as solicitações de especialização no campo da construção estavam, na verdade, atreladas a transformações ainda mais amplas: a constituição e a consolidação da cultura técnica do concreto armado no Brasil, que requisitou, numa conjuntura específica, formação e aperfeiçoamento para seu emprego em grande escala (SANTOS, 2008; FREITAS, 2011).

As exigências próprias do material, a entrada de grandes empresas construtoras no país, o desenvolvimento de pesquisa e inovação tecnológica acirravam as fronteiras de disputa em torno da "ciência" de sua aplicação, fazendo surgir, num movimento de duplo sentido, novos agentes no processo de modernização do país. É na década de 1930 que se estabelece, por exemplo, o Instituto de Pesquisas Tecnológicas em São Paulo, como autarquia que executa, além de ensaios, pesquisas voltadas para atender à indústria; mais adiante, se organiza a Associação Brasileira de Normas Técnicas (ABNT), que determina regras para o emprego de materiais, "padronizando métodos de ensaios e especificação de produtos". Foi a ABNT que estudou e publicou a primeira norma oficial e aplicável de utilização do concreto para todo o país, exatamente no ano de 1940, a NB-1: Cálculo e 
execução de obras de concreto armado (NAGAMINI, 1994, p.126-127). ${ }^{5}$

As teses de Santos (2008) e Freitas (2011) versam também sobre a importância dos canteiros de inovação empreendidos pelas próprias empresas especializadas em concreto que chegam ao Brasil no primeiro quarto do século $X X$, alemãs e dinamarquesas, elas mesmas responsáveis pela formação técnica de engenheiros e arquitetos para a lida com as novidades construtivas de então.

Segundo sistematização feita por Nagamini (1994), em vinte anos, entre 1929 e 1949, são criadas no Brasil 47 empresas ligadas ao setor da construção (soma que exclui as inúmeras já existentes) para atender às demandas de crescimento urbano e infraestrutural do período. Num mercado antes dominado por firmas estrangeiras, começam a despontar aquelas que mais tarde se tornariam as maiores empreiteiras do país, como a SERVIX e a Camargo Correa, abrindo espaço de trabalho para os engenheiros brasileiros. Conforme a mesma autora, toda esta movimentação fez também surgir, paralelamente, os primeiros escritórios especializados em cálculo estrutural:

\footnotetext{
O projeto dos edifícios altos é feito, nessa época, pelas próprias construtoras ou por escritórios de arquitetura; os cálculos estruturais, porém, são levados a efeito por escritórios de cálculo, dirigidos e chefiados por notáveis engenheiros especializados em cálculo de concreto armado. (NAGAMINI, 1994, p. 127).
}

Emílio Henrique Baumgart seria o maior exemplo a citar de engenheiro que, no decurso de todos estes atravessamentos e transformações no

\footnotetext{
5. Segundo Gitahy e Pereira (2002, p. 27), em São Paulo, é na Escola Politécnica, fundada em 1893, que se inaugura o Gabinete de Resistência dos Materiais (1899), "locus em que se institucionaliza a pesquisa tecnológica voltada para a indústria da construção. [...] É para o Gabinete que se voltam as atenções, nos anos 1920, quando vem a público a necessidade de apoio técnico à indústria em acelerado processo de crescimento e diversificação. De fato, o Gabinete autonomiza-se da Escola para atender à demanda por ensaios das empresas, em 1926, transformando-se no famoso Laboratório de Ensaio de Materiais. Em 1934, com apoio material do governo estadual e das empresas privadas, assume novo formato institucional, orçamento próprio e seu atual nome: Instituto de Pesquisas Tecnológicas de São Paulo". É a reunião de laboratórios de materiais visando à elaboração de normas técnicas que leva à criação da ABNT, em 1940. Os empenhos de normalização da construção reforçam, segundo os autores, a articulação daquilo que chamam de "complexo industrial da construção", favorecendo e intensificando a produção civil naquela época, cujo espelho notório seria a verticalização da cidade de São Paulo.
}

campo profissional, se especializa exclusivamente em cálculo, responsabilizando-se pelo dimensionamento estrutural de obras icônicas de nosso repertório arquitetural, caso do edifício do Ministério da Educação e Saúde Pública, de 1938.

Nas palavras esclarecedoras de Santos (2008, p. 175-176):

\footnotetext{
A tecnologia do concreto, sobretudo a normalização de procedimentos, teve um papel importante na consolidação de um lugar distinto para os engenheiros, em que a noção de segurança, associada com o domínio do conhecimento tecnológico, aparece como fonte de legitimação. [...] A partir dos anos 1920, os laboratórios de ensaios de materiais passam a centralizar as experiências relativas às propriedades dos materiais, iniciando a organização do conhecimento e fundamentando a elaboração de normas técnicas para utilização de materiais de construção. O aumento do controle tecnológico significa o aparecimento de mais um poder dentro do campo - os acadêmicos. [...] Dessa forma pode-se considerar a tecnologia do concreto armado como um fator de organização da engenharia civil, pois cria-se em torno do concreto uma aura de complexidade e um certo misticismo em torno das propriedades tecnológicas do cimento e do aço. O mesmo ocorre em relação à organização da obra e ao seu controle tecnológico.
}

Pois, em meio a um processo que não se pode tomar em linearidade, porque, ademais, envolvia não apenas uma metamorfose na configuração produtiva, econômica e territorial do país, mas também disputas ideológicas de toda ordem disputava-se mercado de trabalho, disputava-se um estatuto profissional, disputava-se uma conceituação de arte e de técnica, disputava-se um programa sociocultural, disputava-se uma participação efetiva na modernidade -, embora não haja utilidade em tentar particularizar pioneiros e paladinos nesta história, é impossível, por outro lado, deixar de destacar alguns personagens de reconhecida importância no meio, como, sem dúvida, é o caso de Baumgart e Saturnino de Brito, ainda que em distintas áreas de atuação no campo da engenharia.

Seria possível reconhecer, portanto, no emblema de Baumgart, Brito e outros tantos que como eles delinearam trajetórias similares, uma espécie de "marco-zero" dos engenheiros consultores que mais tarde se autodenominarão como tal. Escritórios como estes (de cálculo e/ou projeto, pareceres, administração, fiscalização) 
pipocaram pelo eixo Rio-São Paulo, sobretudo, a partir da década de 1940. E, aos poucos, começaram a derivar para outras várias áreas de atuação, cumprindo as demandas de mais e mais especialização solicitadas pela própria evolução do ofício. Telles (1993, p. 717-718) encerra a questão:

Desde a segunda metade do século $[X I X]$ até a década de 1920, o grande empregador de engenheiros no Brasil eram as estradas de ferro, vindo em seguida os serviços públicos em geral (sistemas de águas e de esgotos, portos, rodovias, etc.), sendo pequeno o número de engenheiros na atividade que hoje em dia chama-se propriamente "construção civil". O concreto armado, introduzido entre nós a partir dos primeiros anos [do século XX], e cuja vulgarização acentuou-se na década de 1920, alterou completamente esse panorama, porque, daí por diante, a maioria dos engenheiros passou a se dedicar ao concreto armado, na construção civil propriamente dita, e também no projeto e construção de pontes, barragens, muros, etc. Essa evolução da preferência teve reflexos sociais importantes: por um lado, [...] afugentou muitos "engenheiros-práticos" [construtores não-diplomados] e outros curiosos da construção civil [...], por outro lado elevou o "status" social dos engenheiros e propiciou o surgimento e desenvolvimento de numerosas firmas de projeto e construção, algumas das quais transformaram-se depois em importantes organizações de engenharia. Assim, os engenheiros deixaram de ser quase que somente funcionários públicos ou de empresas ferroviárias, passando a dirigir suas próprias empresas de engenharia.

\section{Engenheiros projetistas e consultores: agentes do desenvolvimento territorial e urbano - 1960-1970}

Desde seu surgimento até meados dos anos 1970, segundo Camargo (1994), identificamos um processo gradual de diversificação das empresas de Engenharia Consultiva, que se multiplicam em serviços para atender à demanda, respondendo também a uma política de reserva de mercado de consultoria já estabelecida no país, com a multiplicação de cursos superiores e a regulamentação profissional. ${ }^{6}$

De fato reconhecemos nesses anos a formação de importantes empresas atuantes neste nicho de mercado, com amplo leque de atuação, como é o caso da HIDROSERVICE Engenharia de Projetos Ltda., fundada em 1958 pelo empresário Henry Maksoud, do Consórcio Nacional de Engenheiros Consultores S.A. CNEC - (ainda ativo), criado em 1959, da PROMON, de 1960, e da THEMAG, de 1961 (ambas também ativas). Já nesse momento, caracterizavam-se, a maioria delas, por essa atuação em atividades largamente diversificadas, de escala nacional, como demonstra o anúncio da HIDROSERVICE, listando suas múltiplas áreas de prestação de serviços:

Figura 1: Anúncio da HIDROSERVICE no jornal Folha de S. Paulo (1967).

\section{Engenharia Consultiva Global em Projetos de Desenvolvimento}

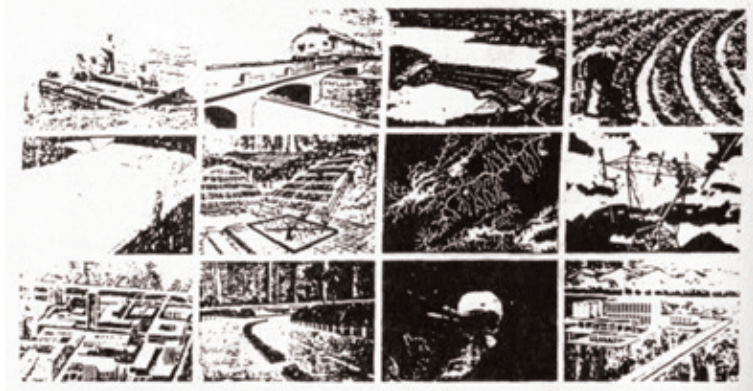

Investigaçōes. Estudos Preliminares de Avaliação

-Planejamento e Planos Diretores •Ante-Projetos, Projetos Básicos e Projetos Executivos.Supervisão da Construcáo e Montagem• Assistência Técnica na Operaçáo e Manutençào de Projetos. Estudos de Viabilidade Tecnica, Econômica eFinanceira.Assessoria em Problemas Especiais.
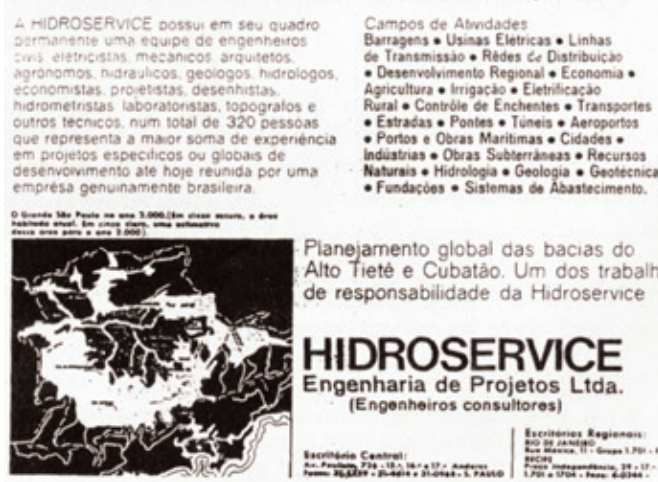

Planejamento global das bacias do Alto tieté e Cubatáo. Um dos trabalhos de responsabilidade da Hidroservice

Fonte: Feldman, 2005a.

Nesse contexto, um fato curioso e importante merece destaque: segundo o cadastro da Financiadora de Estudos e Projetos - FINEP - de 1976, registrado por Feldman (2005a), apenas 20\% das empresas de Engenharia Consultiva formaram-se antes de 1966, ou seja, do ano em que se regulamentou o Serviço Federal de Habitação e Urbanismo - SERFHAU -,

6. Camargo (1994) mostra como gradativamente estas empresas passam a dominar mais e mais os setores estratégicos relacionados ao desenvolvimento territorial e urbano, impulsionadas pelo Estado, entre os anos 1960-1970: depois da entrada no setor das hidrelétricas, em 1957, elas direcionam-se para áreas como transportes, saneamento, meio ambiente $e$ telecomunicações. 
subordinado ao Banco Nacional da Habitação - BNH -, cujo papel seria o de "promover, difundir e uniformizar a prática de elaboração de planos diretores de desenvolvimento, segundo uma postura de integração multidisciplinar, numa perspectiva de racionalidade técnica" e de "neutralidade da atuação governamental", como se pretendendo distanciar-se dos vínculos fisiológicos marcadamente presentes no Estado, valorizando-se "o saber competente, o saber técnico, na elaboração das propostas de intervenção nas cidades" (FERREIRA, 2007, p. 44).

Outros números significativos comprovam o atrelamento da regulamentação do SERFHAU à penetração das empresas de Engenharia Consultiva no setor que se convencionou chamar "desenvolvimento urbano": baseando-se em dados do trabalho de Eurico Azevedo, Sarah Feldman nos mostra que, dos cem municípios analisados pelo pesquisador, $91 \%$ tiveram seus planos diretores realizados a partir de 1967, em período posterior, portanto, à arregimentação do órgão federal. Além disso, a maioria absoluta destes planos acontece pelas mãos das consultoras especializadas $(43,7 \%)$. Sobre elas, Feldman (2005a, p. 230) exemplifica sua forma de atuação:

[...] uma mesma empresa elabora planos diretores para cidades de qualquer parte do Brasil, como também projetos de saneamento, de engenharia civil etc.

\footnotetext{
[...] Um levantamento [realizado sobre os trabalhos desenvolvidos por uma destas empresas, a ASPLAN] aponta que nos anos 1960 a empresa atua na consultoria para os Ministérios da Aeronáutica, Transportes e Planejamento, em grandes projetos de rodovias, abastecimento de água etc.; além disso, elabora planos para inúmeros municípios, como Bragança (1966), Londrina (1968), Mogi das Cruzes (1969), Americana (1970), e também realiza consultorias para o setor privado.
}

A já mencionada HIDROSERVICE, a maior das empresas de Engenharia Consultiva do Brasil nesse momento, desenvolveu, via SERFHAU, o plano de desenvolvimento integrado da região metropolitana de Belo Horizonte, então com 1.200.000 habitantes, entre 1968 e 1969. De um modo geral, ao longo de sua atuação, a empresa reuniu um número bastante expressivo de trabaIhos em seu portfólio, com um grosso de projetos desenvolvidos para o setor público, seja no Brasil, seja em outros países da América Latina e da África, como o Peru, Bolívia, Equador e Nigéria, para os quais se expandiu, sobretudo, a partir da segunda metade dos anos 1970.
As mesmas ASPLAN e HIDROSERVICE são citadas também por Chiquito (2010) como algumas das contratadas pela Comissão Interestadual da Bacia Paraná-Uruguai (CIBPU), criada ainda em 1951, "a partir de um "consórcio para o desenvolvimento regional' entre setes estados brasileiros (Minas Gerais, Goiás, Paraná, Santa Catarina, Mato Grosso, São Paulo e Rio Grande do Sul)". Segundo a pesquisadora, a Comissão cumpriu um papel importante nas experiências brasileiras de planejamento regional no Pós-Guerra, sobretudo no que se refere às teorias e concepções de região e desenvolvimento que mobilizou e também pelo grande número de convênios e contratos firmados com órgãos públicos, instituições, universidades e empresas de consultoria nacionais e internacionais para o trabalho de levantamento, elaboração de projetos e estudos relativos aos estados comissionados, seus recursos naturais, as necessidades das populações da bacia e as possibilidades de desenvolvimento colocadas.

É interessante notar a diversidade de empresas de consultoria que chegaram a desenvolver trabalhos para CIBPU nos seus 21 anos de trajetória: desde a holandesa Deerns Planejamento Engenharia S.A., passando pelo Escritório Técnico Saturnino de Brito, pela Camargo Corrêa S.A., pelas citadas ASPLAN e HIDROSERVICE, até a Sociedade de Análises Gráficas e Mecanográficas Aplicadas aos Complexos Sociais, a SAGMACS (CHIQUITO, 2010).

É evidente, pois, o despertar do interesse econômico empresarial pelo setor de desenvolvimento urbano, acentuado, certamente, no pós64 , a partir da injeção vultosa de recursos gerenciados via BNH, ao qual o SERFHAU estava submetido. Segundo Feldman (2005b), esse período demarcaria, na verdade, o ápice de uma espécie de "tecnicização do urbanismo", em curso no país já desde os anos 1930: a terceirização dos serviços de consultoria especializada para o desenvolvimento dos planos diretores ou, por outra, o empresariamento do planejamento - teria a ver com esse processo, em que se passa ao predomínio de uma "concepção administrativa que tem como principal característica o divórcio entre a atividade técnica e a ação política e cotidiana da administração" (FELDMAN, 2005b, p. 3).

Conforme o registro de Durand (1972, p. 86), do alto dos postos de comando, estes novos "empresários de planejamento", agora imbuídos também da tarefa de criar as diretrizes de ocupação e expansão das cidades, circulavam pelos meandros dos gabinetes políticos, na tentativa de garantir a contratação de planos, 
"enquanto os departamentos financeiros das empresas ocupavam-se com a elevação dos custos (em homem/hora) dos estudos e levantamentos que não cessavam de ramificar-se e aprofundar-se". No nível das "equipes executantes", o clima era de otimismo com a "troca de experiências, de refinamento metodológico, de tentativa de se chegar a proposições viáveis e imediatas", que fossem capazes de corrigir as distorções que a industrialização e a urbanização desenfreadas provocavam do ponto de vista urbano e social no país.

O autor ressalta que a iniciativa privada, aproveitando-se do contexto favorável de ampliação da demanda, absorvia um exército flutuante de especialistas em seus quadros profissionais, e registra, a esse respeito, um significativo depoimento de um arquiteto empregado em uma firma de Engenharia Consultiva de então, que lembra a presença, ali, de técnicos de alta qualificação profissional formados na escola lebretiana e nas experiências do governo Carvalho Pinto, ao mesmo tempo em que reforça o senso de oportunidade de uma HIDROSERVICE, que nasce como uma grande empresa de projetos e mais tarde se expande para o nicho do planejamento integrado, mencionando sua "vastíssima capacidade comercial e penetração no governo" (DURAND, 1972, p. 90).

Nesse contexto, de permeabilidades e trânsitos entre os setores público e privado, em 1966 é criada a Associação Brasileira de Consultores de Engenharia - ABCE -, congregando empresas brasileiras de engenharia atuantes, no ramo da consultivo, em diferentes setores de infraestrutura, indústria, mineração, energia, petróleo e gás, transportes, recursos hídricos e saneamento, meio ambiente etc., demonstrando, mais do que tão somente a ampliação da demanda por serviços dessa natureza, sobretudo o nível de organização deste campo profissional no período.

Os números de expansão corporativa do setor registrados por Camargo (1994) demonstram um período de bonança que engloba toda a década de 1970: com a permanência dos investimentos em áreas estratégicas da economia brasileira, que começou a apresentar sinais claros de recessão apenas na virada para os anos 1980, muitas empresas de Engenharia Consultiva chegam a ultrapassar 2.000 funcionários à época, constituindo corpos técnicos qualificados, reunidos em equipes multidisciplinares. A PROMON, por exemplo, que entre 1960 e 1965 contava com uma média de apenas sessenta funcionários, chega a 1986 com 4.140 empregados, exatamente no momento em que o campo profissional vê-se obrigado a se reinventar para enfrentar a crise que exauria o setor produtivo nacional (CAMARGO, 1994).

\section{Observações finais}

Presentes em algumas poucas narrativas em parte dedicadas ao estudo sobre os saberes e experiências de produção da cidade, ${ }^{7}$ é importante que se diga que os especialistas da Engenharia Consultiva e a atuação destas empresas no ramo do desenvolvimento territorial e urbano ainda não mereceram da historiografia um olhar mais atento e focalizado. Nesse sentido, as reflexões aqui presentes pretendem ser também uma espécie de estímulo ao início desta empreitada acadêmica, de modo que possamos alargar as fronteiras do conhecimento já acumulado sobre a prática profissional dos planejadores e produtores do território, e, mais do que disso, sobre a própria história da urbanização brasileira.

\section{Referências}

AZEVEDO, E. de A. Avaliação do Planejamento Municipal no Estado de São Paulo. Relatório de Pesquisa. São Paulo: FAPESP/USP/EESC, 1976.

CAMARGO, T. A. M. B. H. As empresas de projeto de engenharia de grande porte no Brasil: passado, presente e a reengenharia para o futuro. 1994. Tese (Doutorado) - Escola Politécnica, USP, São Paulo, 1994.

CHIQUITO, E. A. A Comissão Interestadual da Bacia Paraná-Uruguai (CIBPU) e o planejamento regional no Brasil (1951-1972). In: ENCONTRO DA ASSOCIAÇÃO NACIONAL DE PESQUISA E PÓS-GRADUACÇÃO EM ARQUITETURA E URBANISMO: Arquitetura, Cidade, Paisagem e Território - Percurso e Prospectivas, 1., 2010, Rio de Janeiro. Anais... Rio de Janeiro, 29 nov.-10 dez. 2010.

DURAND, J. C. G. Arquiteto: estudo introdutório de uma ocupação. Tese (Doutorado) - FFLCHUSP, São Paulo, 1972.

FELDMAN, S. Planejamento e Zoneamento: São Paulo, 1947-1972. São Paulo: Edusp/Fapesp, 2005a.

O Arranjo Serfhau: Assistência Técnica aos Municípios/Órgãos de Planejamento/ Empresas e Engenharia Consultiva. In: ENCONTRO NACIONAL DA ANPUR, 11., 2005, Salvador. Anais... Salvador, maio 2005b.

7. Como nos trabalhos de Feldman (2005a, 2005b). 
FERREIRA, M. Planejamento urbano nos tempos do SERFHAU: o processo de construção e implementação do Plano Diretor de Desenvolvimento Integrado de Franca. 2007. Tese (Doutorado) - EESC-USP, São Carlos, 2007.

FICHER, S. Os arquitetos da Poli: ensino e profissão em São Paulo. São Paulo: FAPESP/Edusp, 2005.

FREITAS, M. L. de. Modernidade concreta: as grandes construtoras e o concreto armado no Brasil, 1920 a 1940. 2011. Tese (Doutorado) FAU-USP, São Paulo, 2011.

GITAHY, M. L. C.; PEREIRA, P. C. X. (Org.). O complexo industrial da construção e a habitação econômica moderna, 1930-1964. São Carlos: RiMa, 2002.

NAGAMINI, M. Construção de edifícios e engenharia urbana. In: MOTOYAMA, S. (Coord.). Tecnologia e industrialização no Brasil: uma perspectiva histórica. São Paulo: Ed. da UNESP/ CEETEPS, 1994.

SANTOS, R. E. dos. A armação do concreto no Brasil: história da difusão da tecnologia do concreto armado e da construção de sua hegemonia. Tese (Doutorado) - Faculdade de Educação da UFMG, Belo Horizonte, 2008.

TELLES, P. C. da S. História da Engenharia no Brasil: século XX. Rio de Janeiro: Clavero Editoração, 1994. 